Google in the Research and Teaching of Instruction Librarians

Charlene Sorensen Serials Coordinator University of Saskatchewan Library charlene.sorensen@usask.ca

\section{Candice Dahl}

Liaison and Instruction Librarian

University of Saskatchewan Library candice.dahl@usask.ca 


\begin{abstract}
This exploratory study assesses the differences and similarities between how instruction librarians in Western Canada use Google and how they instruct students to use it. Survey results indicate that these librarians do use Google but can be influenced by faculty to present Google negatively to students.
\end{abstract}

\title{
INTRODUCTION
}

The use of Google as a research tool is widespread among undergraduate students. Anecdotal observations from librarians, faculty members, and students themselves attest to this fact, as do a number of studies on student searching behaviors. ${ }^{1}$ Anecdotal observations also reveal that both faculty members and librarians have conflicted responses to this reality. Faculty concern with student use of Google is not uniform but, when present, sometimes leads to overly broad and misguided prohibitions regarding the use of online information as a whole. There are both librarians and faculty who express concern when Google is used for research and when it becomes a replacement for research tools accessible primarily through libraries. But there are also librarians who recognize the usefulness of Googling in many research quests. Many are in fact 'closet Googlers' - they are uncomfortable publicly admitting their level of Google use, and share such information as a sort of 'confession' - who feel pressured by the tenets of the library profession, their colleagues, and sometimes even the faculty members in whose courses they provide instruction, to espouse an excessively cautious, if not manifestly negative, attitude toward Google. 
The authors hypothesized that differences exist between the purposes for which librarians use Google themselves and the purposes for which they teach students to use Google when providing in-class instruction at the request of faculty. A second hypothesis was that where these discrepancies existed, they would be due in part to the faculty members themselves. Since personal search experiences and system knowledge can influence the kind of training and advice that instructors provide, ${ }^{2}$ the authors considered the personal practices of librarians alongside their instructional practices. A survey was designed to investigate how and why instruction librarians use Google, how their own use of it for research either contradicts or aligns with what they teach, and whether or not what they teach about Google is influenced by faculty.

The survey results provide a preliminary backdrop against which librarians could assess their own practices and explore some of the issues related to using Google and teaching about it. The findings shed light on how instruction librarians use Google for research, faculty influences on library instruction, and the purposes for which Google is presented to students. These conclusions provide a starting point for discussion and reflection on how shifting attitudes toward Google and librarians' own practices impact library instruction.

\section{LITERATURE REVIEW}

This research investigates why Google is used and how it is handled by librarians in instructional settings, and so must be situated in the context of research on student and faculty perspectives on Google, the information-seeking 
behavior of librarians, and librarian attitudes toward Google as a research tool. Though no other study sets out to determine how instruction librarians use and teach about Google, the findings about these related issues inform our understanding of Google's contested place in current research practices.

What is evident in the literature is a negative attitude toward using Google for academic research. Starting in the 1990s, as more and more people had better and faster access to the ever-growing Web, the librarian was no longer the necessary intermediary between the user and information; libraries now had competition. ${ }^{3}$ A common reaction from librarians was to condemn the use of Google and cite it as the reason why students were ignoring academic library resources. Yi acknowledges the need to "fight against research by 'Googling"”4 and Pennavaria states that Google is "a bad place to start an academic research paper". ${ }^{5}$ Explanations for the allure of Google include Griffiths and Brophy's study of student searching behavior that describes the "age of information satisfying", where users are satisfied with a few relevant hits. ${ }^{6}$ Brophy and Bawden's comparison of Google and library databases refers to Zipf's "principle of least effort" and Simon's concept of "satisficing", which they identify as natural human impulses to accept convenient access to information that is good enough. ${ }^{7}$ Several studies have investigated how students use the Web, including either Google specifically or search engines in general, and there is wide recognition that Google is a frequently-used research tool. ${ }^{8}$ Attitudes of faculty members toward student use of open Web resources, including Google, have also been investigated, revealing a certain level of dissatisfaction with the 
resources that students find there. ${ }^{9}$ There have been both recent and older analyses of the use of the Internet and Web as an information resource. While Brinkley and Burke compared Hytelnet, Gopher, Archie, WAIS and the World Wide Web in 1995, more recently Brophy and Bawden compared Google with academic library systems and resources. ${ }^{10}$ These studies highlight a widespread tension between the research practices of students and the expectations of faculty. This finding led the authors of this paper to investigate the influence of faculty on the content of library instruction sessions.

While a significant amount of research has been done about the information-seeking behavior of different segments of the population ${ }^{11}$ and Web information-seeking behavior, ${ }^{12}$ very little has been written specifically about the information-seeking behavior of librarians themselves. Brown and Ortega have studied information-seeking activities used by physical science librarians to inform their practice,${ }^{13}$ but how these activities inform a librarian's own research activities is not known. That is, we do not know to what extent librarians rely on Google when conducting their research. Interest in determining the relationship between what librarians practice and what they teach led the authors of this paper to further investigate their use of Google.

The extent to which Google is addressed in library instruction sessions, and the stances that instruction librarians take toward it have only been touched on indirectly. Harley, Dreger and Knobloch advocate an increased instructional focus on developing critical thinking skills in order to help students navigate the Web more effectively. ${ }^{14}$ Colaric concludes that instruction focused on increasing 
student understanding of how search engines work equips them to use search engines more effectively. ${ }^{15}$ Doyle and Hammond suggest teaching students several criteria with which to evaluate Web sources, ${ }^{16}$ though Becker's earlier study found that even though "students could discuss the critical role of quality assessment of Websites ... they rarely applied the criteria in the searches they described." ${ }^{17}$ While suggestions have been made regarding how to teach about search engines in general, no studies of the actual instructional practices of librarians have been carried out. Thus, the authors of this paper set out to fill in the picture of how Google is being addressed in library instruction.

Given the high profile and increasing importance of Google in our current research environment and the varying attitudes toward it evidenced in the professional literature, it is timely and important to better understand both how librarians use Google themselves and how they approach it while conducting library instruction. As there is nothing in the literature that addresses these questions directly, our research makes a unique contribution to discussion of these topics.

\section{Methodology}

A Web-based survey, created using SurveyMonkey, was distributed to all instruction librarians in the humanities and social sciences who work in libraries belonging to the Council of Prairie and Pacific University Libraries ${ }^{18}$, a consortium of twenty university libraries in Manitoba, Saskatchewan, Alberta, and British Columbia. A list of names and contact information for the 144 librarians 
that fit this profile was gleaned from the Web sites of the member libraries. Librarians from specific institutions were contacted via email when clarification was required to complete the list.

A personalized invitation was e-mailed to all members of the target population, in which they were informed that their names would be entered into a draw for one of three $\$ 50$ gift cards from Chapters/Indigo whether or not they participated in the study. Three days later, a generic email with complete information about the study and a link to the survey was sent out. Ten days later, a reminder email that also included a link to the survey was sent to everyone. Survey data was collected over two weeks in February and March 2007 and later analyzed using standard statistical software (SPSS 15.0).

The survey consisted of twenty-two questions, five of which were openended. The remaining questions were partially closed-ended questions with ordered and unordered response categories. The responses to the closedended questions were entered into an SPSS database to compute frequencies and make statistical comparisons. The responses of the open-ended questions were aggregated to represent the essence of the responses. Specifically, the survey addressed five areas:

- confirmation that participants conduct formal library instruction (only participants who answered "yes" could proceed with the survey)

- demographic information about the participants

- personal use of Google for academic research

- treatment of Google in formal library instruction sessions 
- faculty influences on library instruction

For clarification purposes, the survey introduction included a statement that defined formal library instruction to include in-class or course-related instruction at the request of faculty, teaching one's own course, and teaching library skills sessions or information literacy initiatives. This definition was intended to eliminate instruction provided during reference consultations. The survey also included a statement defining academic research as any investigation/inquiry undertaken in order to gather data or information needed for scholarly work and/or professional practice. Google was defined as the Google search engine and its search products. Recognizing that some Google products specialize in more academic resources and might be treated differently by some respondents, the survey included two open-ended questions in order to capture more detail on how the participants used these products.

\section{RESULTS}

The final realized sample was a total of 71 usable surveys, representing a 49 percent response rate. Although the sample of respondents was comparable to the population sampled as a whole, it is important to keep in mind that the results of this survey should be viewed with caution as there may be inherent differences between those who chose to respond and those who did not. Table 1 summarizes the demographic profile of the respondents. Two-thirds of the respondents were female, which is comparable to the results of two recent Canada-wide surveys of academic librarians ${ }^{19}$. Most of the respondents were in 
the 30-39 and 50-59 age groups, with only ten percent of the respondents either under the age of thirty or over the age of sixty. Forty-one percent of the respondents obtained their library science degree in the current decade.

[Table 1 here]

\section{Librarians' Use of Google}

Although this study did not set out to paint a complete picture of the information-seeking behavior of instruction librarians, it does provide insight into their use of Google for their own academic research. When asked, "Do you use Google in any way when conducting academic research?", only 13 out of the 67 respondents (19.4 percent) selected "No". When asked to explain why not, the 13 respondents generally indicated that they try to use it but are often disappointed, that they don't use it exclusively, and that they use it only for finding certain kinds of information.

The respondents were also asked to rate the extent to which they agree or disagree about five possible reasons for using Google for academic research on a five-point Likert scale that ranged from 1 ("strongly disagree") to 5 ("strongly agree"). Fig. 1 provides the mean (average) scores of the responses for each of the reasons. Respondents more often agreed than disagreed that they use Google for academic research because it is a fast way to find information (mean $=3.8)$, it is easy to use (mean $=3.6)$, and it is good starting point (mean $=3.52$ ) since they had mean scores that fell between 3 (neither agree nor disagree) and 
4 (agree). Respondents more often disagreed than agreed that they use Google for academic research because they find most of what they need there (mean = 2.11) since the mean score fell between 2 (disagree) and 3 (neither agree nor disagree). The responses to these two questions indicate that most of these librarians are using Google because it is fast and easy to use, but it is not their only source for academic research.

[Figure 1 here]

In order to encourage respondents to comment more specifically on why they use Google for their own research, an open-ended question was included in the survey. When asked, "Please describe other reasons you use Google for your academic research (if any)", two overall themes were found within the 25 responses. First, responses indicate that Google is used at certain points of the research process. Google is used as a starting point for research for some, while for others it is used as a last resort if they are finding little elsewhere. The other theme identified was that the respondents used Google to find specific kinds of information not typically indexed in library databases, such as government information, grey literature, statistical information, conference presentations, and news items.

The responses to the closed and open-ended questions indicate that convenience is a factor for librarians, just as it is for students, when selecting research tools. They also reveal certain strengths of Google and the particular 
shortcomings that prevent librarians from regarding it as a comprehensive research tool.

\section{Academic Research vs. Library Instruction}

In order to compare the actual research practices of librarians with the practices they promote to students during formal library instruction, the study aimed to discover whether or not instruction librarians teach students to use Google differently than they use it themselves.

Two similar questions were posed, each from a different perspective. The respondents were first asked to indicate, on a five-point scale that ranged from 1 ("never") to 5 ("all of the time"), how often they teach the use of Google to find seven different kinds of information. The related question asked respondents to indicate how often they use Google to find the same seven kinds of information themselves. Figure 2 compares the mean (average) responses to these questions. A paired samples t-test determined the significance of the distribution.

[Figure 2 here]

The responses indicate that these librarians both teach and use Google to find all of the types of information to some extent, although respondents use Google significantly more often than they teach students to use it to find personal/contact information, just to see what exists, background information, definitions, and bibliographies. One possible explanation for this difference is 
that Google can be easily used to find certain types of information and therefore it is not a skill that the librarians feel the need to address during formal library instruction. Another possibility is that librarians focus on academic information in the narrowest sense (i.e. peer-reviewed journal articles and academic books) during instruction sessions and therefore do not address what might be considered more peripheral information sources in that context. In fact, no difference was found between how often Google is used by the librarians and how often they teach students to use it for scholarly information and journal articles.

Though Google is used by librarians for a variety of research purposes, there is a significant difference between the frequency with which these librarians use Google to find specific types of information themselves and the frequency with which they teach students to do so. Though there may be a whole range of causes for this discrepancy, one possible cause investigated here was that of faculty influence.

\section{Faculty Influence}

The authors initially hypothesized that discrepancies between how librarians use Google themselves and how they teach students to use Google were due in part to faculty themselves. Therefore, respondents were asked two questions that attempted to evaluate the extent to which faculty influenced their formal library instruction sessions. The respondents were first asked to indicate, on a five-point scale that ranged from 1 ("never") to 5 ("all of the time"), how 
frequently they receive guidelines from faculty for acceptable use of Google by students. The responses presented in Fig. 3 indicate that seventy-five percent of the participants receive guidelines at some point, though very few receive guidelines all of the time.

[Figure 3 here]

Two questions were then posed in order to try to determine if these faculty guidelines resulted in Google being presented differently in a formal library instruction session than if no guidelines were provided to the librarians. When asked "How frequently do instructions from faculty encourage you to do each of the following when teaching in their classes" and "In the instances where course instructors have not provided you with specific directives regarding the use of Google, how do you address Google in class", there were significant differences in frequency for three of the four options provided. Fig. 4 compares the mean (average) responses to these questions. A paired samples t-test determined the significance of the distribution.

[Figure 4 here]

The responses reveal that when given guidelines by faculty, the frequency with which librarians present Google as a supplement to other research tools (mean $=2.03)$ is significantly less than when they teach without faculty guidelines 
(mean $=3.15)$. They also present Google as a viable option for scholarly information less frequently when they have guidelines $($ mean $=1.86)$ than when they have not been provided guidelines by faculty (mean $=2.57)$. The librarians also recommend that students not use Google at all significantly more often when faculty provided them with guidelines for the class (mean $=2.23$ ) than if they did not $($ mean $=1.42)$. That is, librarians mention Google positively in instruction sessions more often when they do not have guidelines from faculty.

\section{Discussion}

The data gathered through this exploratory survey highlights several points for instruction librarians to consider when deciding the extent to which they should provide instruction on the use of Google and how to approach it.

\section{An Acceptable Research Tool}

This study confirms that librarians included in this study are using Google when conducting their own research to some extent, and most often for finding personal or contact information, background information, and what already exists on a particular topic. Since it is not unreasonable to assume that personal practices impact upon the content and design of the library instruction librarians provide,$^{20}$ librarians should reflect on these personal practices.

The practices of both librarians and undergraduates demonstrate that ways of doing research are expanding to include the use of available technologies and the kind of resources that the Web makes more readily 
available. The research habits of undergraduates certainly indicate that a reliance on traditional search methods and tools is not the norm. Library instruction must be responsive to these changes and confront the possibility that the way, even the 'right' way, of doing research is changing and expanding. Instruction librarians must give serious thought to how they approach Google in instructional situations, especially since Google itself continues to develop products (i.e. Google Scholar and Google Books) to ensure its place in the world of researchers. Librarians might redouble their efforts to create in students a sophisticated understanding of issues surrounding online research and authority that transcend the question of whether or not to use Google and to provide students with real, helpful research strategies.

The survey results suggest that most of these academic librarians believe that Google can be easy to use, a fast way to find information, and a good starting point. This recognition reveals that they are much like their students, who are understandably drawn to quick and simple search tools. The difference, perhaps, is that librarians generally do not stop with Google, though it may be where the students stop. It is clear, however, that both students and academic librarians are using Google for research, so portraying it as a viable option makes more sense than ignoring it altogether or focusing on its inadequacies.

\section{Faculty Influence}


Although not specifically investigated in this study, others have found that one faculty response to students' lack of critical assessment of the information they find online is to impose stricter limitations on the online search tools and sources that students are allowed to use. ${ }^{21}$ For example, unhappiness with poorly researched papers has led to prohibitions on using the Web, Google specifically, and other resources such as Wikipedia. This study supports this finding, as the participants presented Google as a viable research tool less frequently when they were given instructions from faculty about how to present Google in their classes.

Librarians must work with faculty to unearth the real issues they have with their students using Google. Is it just that some of the information students find there is not academic? The same could be said of subscription databases that include popular sources alongside academic ones. Is it that students can sometimes write a paper without actually using library resources? Or is the issue that students are actually sidestepping the linear process of conducting research to which many faculty members are accustomed?

Regardless of what faculty require and librarians teach, recent studies indicate that the majority of students do use Google and other search engines before going to their library's Web resources - if they get to them at all. How does this influence the work of librarians who provide instruction at the request of faculty? This can be a difficult situation, especially since faculty appear to discourage librarians from presenting Google positively, and since it has been acknowledged that academic staff (i.e. faculty and course instructors) "exert a 
greater influence over undergraduate and postgraduate use of electronic information systems than library staff'" ${ }^{22}$

In trying to bridge the divide between faculty and students (when it is necessary to do so) some librarians provide students with evaluation criteria for Web sites or show only appropriate or allowable online resources. These approaches, however, do not prove to be fully adequate. As the academic community begins to acknowledge that ways of doing research are changing and that it is becoming easier to access a larger variety of resources via Google, many of which are valuable though they cannot be adequately evaluated using traditional criteria, a better understanding of online research must be fostered. Students must develop the critical apparatus necessary to determine what information is appropriate for their needs, without which their level of information literacy remains questionable.

Debates about the role of Google in research should move away from the question of whether or not to use Google as a research tool, but focus instead on the movement to encourage critical thinking and teach adequate skills of evaluation so that using Google for research is perceived as an opportunity rather than an impediment. Then librarians can address Google in their classes as the kind of tool that can be as useful for students as it is for themselves. Instead of attempting to either combat or dismiss Google, instruction librarians might consider "Google's role as teacher" and "be aware of its influence both to help students search well and to understand their frustrations with library systems. ${ }^{23}$ 


\section{CONCLUSION}

The increasing popularity of Google has contributed to the emergence of new ideas about research that are as varied as the practices and preferences of the undergraduates, faculty and librarians who use it. Google is gaining ground as a tool for conducting academic research, which has made it the focus of attention and debate in discussions of undergraduate research. It is therefore timely to assess the implications of this development on the practices of instruction librarians and the instruction they provide, and identify issues to consider. By investigating the purposes for which instruction librarians use Google for research, the ways in which their personal use of it differs from what they teach students about it, and the type of influence exerted by faculty, this study has provided some insight into the place of Google in the research and teaching of instruction librarians. This insight will assist instruction librarians when working with faculty members and undergraduates, and when planning library instruction, by encouraging them to think about their attitudes toward, and uses of, Google and its place in academic research. The considerations raised in this paper provide a starting point and invite further investigation into these issues. 
1. Nancy J. Becker, "Google in Perspective: Understanding and Enhancing Student Search Skills," New Review of Academic Librarianship 9 (2003): 84100 ;

Jillian R. Griffiths \& Peter Brophy, "Student Searching Behavior and the Web: Use of Academic Resources and Google," Library Trends 53 (2005): 539-554; "Student Searching Behavior"; OCLC White Paper on the Information Habits of College Students. Online Computer Library Center. (2002) Available: http://www5.oclc.org/downloads/community/informationhabits.pdf (November 2, 2007);

Steve Jones, The Internet Goes to College: How Students are Living in the Future with Today's Technology. Pew Internet and American Life Project. (2002) Available: http://www.pewinternet.org/pdfs/PIP_College_Report.pdf (November 2, 2007).

2. Ina Fourie, "Learning from Web Information Seeking Studies: Some Suggestions for LIS Practitioners," The Electronic Library 24 (2006): 20-37.

3. Carla Stoffle et al., "Continuing to Build the Future: Academic Libraries and their Challenges," Portal: Libraries and the Academy 3 (2003): 363-380.

4. Hua Yi, "Library Instruction Goes Online: An Inevitable Trend," Library Review 54 (2005): 47-58.

5. Katherine Pennavaria, "Down with Google! Better Source Selection for Students," Kentucky Libraries 67, no. 2 (Spring 2003): 11-13.

6. Griffiths \& Brophy, "Student Searching Behavior". 
7. Jan Brophy \& David Bawden, "Is Google enough? Comparison of an Internet Search Engine with Academic Library Resources," Aslib Proceedings 57 (2005): 498-512.

8. Becker, "Google in Perspective";

Griffiths \& Brophy, "Student Searching Behavior;

OCLC White Paper;

Jones, "The Internet Goes to College".

9. Deborah J. Grimes \& Carl H. Boening, "Worries with the Web: A Look at Student use of Web Resources," College \& Research Libraries 62 (January 2001): 11-23;

Nicholas G. Tomaiuolo, "Faculty Views of Open Web Resource use by College Students," The Journal of Academic Librarianship 31 (2005): 559566 ;

Necia Parker-Gibson, "From the Womb to the Web: Library Assignments and the New Generation," Reference Librarian 91/92 (2005): 83-102.

10. Monica Brinkley \& Mary Burke, "Information Retrieval from the Internet: An Evaluation of the Tools," Internet Research 5, no. 3 (1995): 3-10; Brophy and Bawden, "Is Google enough?".

11. Donald O. Case, Looking for Information: A Survey of Research on Information Seeking, Needs, and Behavior (Amsterdam: Academic Press, 2002). 
12. Bernard J. Jansen \& Udo W. Pooch, "A Review of Web Searching Studies and a Framework for Future Research," Journal of the American Society for Information Science and Technology 52 (February 2001): 235-246.

13. Cecelia M. Brown \& Lina Ortega, "Information-Seeking Behavior of Physical Science Librarians: Does Research Inform Practice?" College \& Research Libraries 66 (May 2005): 231-247.

14. Bruce Harley, Megan Dreger \& Patricia Knobloch, "The Postmodern Condition: Students, the Web, and Academic Library Services," Reference Services Review 29 (2001): 23-32.

15. Susan M. Colaric, "Instruction for Web Searching: An Empirical Study," College and Research Libraries 64 (March 2003): 111-122.

16. Tony Doyle \& John L. Hammond, "Net Cred: Evaluating the Internet as a Research Source," Reference Services Review 34 (2006): 56-70.

17. Becker, "Google in Perspective," p. 90.

18. Excluding the University of Saskatchewan, the home institution of the researchers.

19. 8Rs Research Team, The Future of Human Resources in Canadian Libraries (February 2005), www.Is.ualberta.ca/8rs/8RsFutureofHRLibraries.pdf; David Fox, "A Demographic and Career Profile of Canadian Research University Librarians," Journal of Academic Librarianship 33 (2007): 540-550.

20. Fourie, "Learning from Web".

21. Carol A. Wright, "The Academic Library as a Gateway to the Internet: An Analysis of the Extent and Nature of Search Engine Access from Academic 
Library Home Pages," College and Research Libraries 65 (July 2004): 276300.

22 Griffiths \& Brophy, "Student Searching Behavior," p. 543.

23 Pamela Martin, "Google as Teacher: Everything Your Students Know they Learned from Searching Google," College \& Research Libraries News 67 (February 2006): 100-101. 